\title{
Measuring the Size of Output Gap in Sukuk Issuing OIC Member Countries
}

\author{
Nursilah Ahmad, PhD \\ Norhaziah Hashim \\ Fuadah Johari
}

Faculty of Economics and Muamalat, Universiti Sains Islam Malaysia (USIM), Bandar Baru Nilai1, 71800, Nilai, Negeri Sembilan, Malaysia nursilah@usim.edu.my

\section{Doi:10.5901/mjss.2015.v6n2s5p249}

\section{Abstract}

The aim of this study is to estimate the size of output gaps for sukuk issuing Organization of Islamic Cooperation (OIC) member countries. The output gap is measured based on univariate Hodrick-Prescott (HP) filter for the period 1980 until 2011. Data are sourced from the World Economic Outlook and SESRIC databases. The findings reveal that Bahrain, Pakistan and Malaysia have smooth trend between real GDP and its trends. Most countries display fewer fluctuations in business cycles and changes in inflation during mid-2000s. The results suggest that output gap estimations contain key information for monetary policy since the estimate of output gap can contribute towards identifying and assessing the effectiveness of monetary policy framework over time. For cross-border sukuk issuance, the ability to sustain economic growth in the long run without inducing inflation will boost investors' confidence.

Keywords: Sukuk, output gap, HP filter, inflation, Islamic finance, OIC economies

\section{Introduction}

One of the important issues in macroeconomics is understanding macroeconomic fluctuations. One way to measure the fluctuations is by estimating output gap. Output gap, or business cycle, is defined as the difference between actual and potential output. Potential output is an unobservable variable that reflects the maximum output an economy can sustain without inducing inflation. It is the level of Gross Domestic Product (GDP) that is consistent with full utilisation of all factors of production under conditions of stable inflation. Since output gap is unobservable, it has to be estimated.

Output gap captures the effect of shifts in domestic demand thus represents demand shocks. Higher domestic demand would tend to raise domestic and import prices (Bussiere, 2006). Output gap captures the notion that with increasing sales, firms are more likely to pass-through increases in costs to final prices. The reverse is also true. Therefore, the current output gap estimations should provide information regarding future inflation. Since economic policies have direct impact on the size of the gap, the gap model is central to almost all inflation models.

The present study contributes to the Islamic financial economics literature by investigating whether the degree of excess capacity in the economy is an important determinant of inflation in sukuk issuing Organization of Islamic Cooperation (OIC) member countries. The countries involved in the study are Brunei, Bahrain, Indonesia, Kuwait, Malaysia, Pakistan, Qatar, Saudi Arabia, Turkey and the United Arab Emirates (UAE). Sudan is excluded due to data constraints. Since inflation is one of the key determinants affecting sukuk performance the present study investigate whether output gap estimation is a good indicator of inflationary pressures for these economies. The present research contributes to the Islamic finance literature by attempting to examine the issue from output gap perspective.

The remainder of the paper is organized as follows. Section 2 discusses literature review. Section 3 examines the research method while Section 4 presents the findings. Section 5 concludes the discussion.

\footnotetext{
1 The research is funded by Universiti Sains Islam Malaysia (USIM) Research Grant PPP/FEM/IWM/30/14112.
} 


\section{Background}

\subsection{Output Gap}

There are at least five different methods of estimating output gap namely linear time trends, Hodrick-Prescott (HP) filter trends, multivariate HP filter trends, unobservable components models and a production function model. In general, these methods produced similar broad time profile of the output gap (deBrouwer, 1998). Coe and McDermott (1997) find the estimated output gap is in the range of \pm 3 percent for the 13 Asian economies under their investigation.

Output gaps are estimated for two reasons. Firstly is to provide information about excess capacity in the economy at a particular point in time. From the perspective of monetary policy, the output gap over the forecast horizon is of most interest. Secondly, time series of the output gap is to be used in modelling exercises. The inclusion of output gap produce better estimates of inflation. For example, given that excess demand pressures are a key driver of rising inflation, the output gap can be included in price or wage inflation equations to obtain a more precisely estimated equation and more accurate forecasts (deBrouwer, 1998). Hence, the importance of output gap in macroeconomic models is due to its importance in assessing inflationary pressure and the cyclical position of the economy.

Potential output and output gap estimates also help to assess macroeconomic policies. The estimate of output gap can contribute to identifying and assessing patterns of monetary policy framework over time. A positive output gap is indicative of demand pressures and a signal that inflationary pressures are increasing and that policy may need to tighten. A negative output gap has the opposite implication.

\subsection{Sukuk Issuance}

Table 1 below shows the regional break-up of sukuk issuance country over the period 2001 to 2010. The Gulf Cooperation Council (GCC) and Middle East Countries dominate in terms of number of issuance and percentage of total value. The United Arab Emirates (UAE) has the highest percentage of total value (in USD million) of 52 percent, followed by Malaysia and Bahrain each contributed 12 percent and Saudi Arabia - 11 percent. The United States, United Kingdom, Japan and Turkey represent only two percent of the overall international issuance. Based on the current trend, sukuk are most likely to be issued in the Asia and the Far East and the GCC and Middle East economies in the future.

Table 1: Regional Breakdown of Total International Sukuk Issuance, 2001- 2010

\begin{tabular}{cccc}
\hline Asia \& Far East & Amount (USD million) & Number of Issues & $\%$ of Total Value \\
\hline Malaysia & 5,496 & 12 & $12 \%$ \\
Indonesia & 650 & 1 & $1.4 \%$ \\
Pakistan & 600 & 1 & $1.3 \%$ \\
Brunei Darussalam & 200 & 2 & $0.42 \%$ \\
\hline Total & 6,946 & 16 & $15 \%$ \\
\hline GCC \& Middle East & Amount (USD million) & Number of Issues & $\%$ of Total Value \\
\hline Bahrain & 5,633 & 90 & $12 \%$ \\
Qatar & 2,020 & 4 & $4 \%$ \\
Saudi Arabia & 5,440 & 9 & $11 \%$ \\
UAE & 25,050 & 30 & $52 \%$ \\
Kuwait & 1,575 & 9 & $3 \%$ \\
\hline Total & 39,718 & 142 & $83 \%$ \\
\hline Africa & Amount (USD million) & Number of Issues & $\%$ of Total Value \\
\hline Sudan & 130 & 1 & $0.3 \%$ \\
\hline Total & 130 & 1 & $0.3 \%$ \\
\hline Others & Amount (USD million) & Number of Issues & $\%$ of Total Value \\
\hline Japan & 100 & 1 & $0.2 \%$ \\
Turkey & 100 & 1 & $0.2 \%$ \\
UK & 271 & 2 & $0.6 \%$ \\
USA & 600 & 2 & $1.3 \%$ \\
Total & 1,071 & 6 & $2 \%$ \\
\hline Grand Total & 47,865 & 165 & $100 \%$ \\
\hline & & &
\end{tabular}

Source: IIFM Sukuk Issuance Database (Jan. 2001 - Dec. 2010) and Sukuk Annual Report 2011. 
In short, the economic structure and level of development of a country will determine the appropriate exchange rate regime. In developing countries, with fairly new financial systems, trade variables will most likely determine the exchange rate. For the developed economies, the movements of capital and financial assets will affect exchange rates. Hence, selecting appropriate exchange rate arrangements and moving from a fixed to flexible regime requires a good understanding of macroeconomics fluctuations.

\section{Method}

The sample consists of ten OIC sukuk issuing member countries. Data are annually, covering the period from 1980 to 2011 and are sourced from the World Economic Outlook Database. For annual data, Gross Domestic Product (GDP) is used as the proxy for real output and trend estimates. The study also includes data on annual percentage changes in Consumer Price Index (CPI). Data are in log values, in constant USD 2005 prices. Output gap is measured in growth rates and CPIs are measured in percentage changes.

Output gap is estimated as the log difference between actual output and its Hodrick-Prescott (HP) filter. The Hodrick-Prescott filter (HP filter) decomposes output into permanent and transitory components generating a smoothened trend of output. The generated smoothened series is the estimated potential output. The HP filter is defined as follows.

Suppose a time series ygapt can be decomposed into trend (growth) component, $\operatorname{ygap}_{t}^{g}$ and cyclical component, ${ }^{\operatorname{lgap}_{t}^{c}}$ :

$$
\operatorname{ygap}_{t}=\operatorname{ygap}_{t}^{g}-y g a p_{t}^{c}
$$

The HP filtering process will choose the growth component, $y g a p_{t}^{g}$ that minimize the following problem:

$$
\operatorname{Min}(1 / T) \sum_{t=1}^{T}\left(\text { ygap }_{t}-\text { ygap }_{t}^{g}\right)^{2}+(\lambda / T) \sum_{t=2}^{T-1}\left[\left(\text { ygap }_{t+1}^{g}-\operatorname{ygap}_{t}^{g}\right)-\left(\operatorname{ygap}_{t}^{g}-y g a p_{t-1}^{g}\right)\right]^{2}
$$

where $T$ is the sample size. The first term is the sum of the squared deviations and indicates the goodness of fit. The second term is the sum of the squares of the trend component's second differences and measure the degree of smoothness. The parameter $\lambda$ is the smoothness parameter, set at 100 for the annual data, following the literature in the subject. The $\lambda$ parameter penalizes the variability in the growth component. If the value of $\lambda$ is zero, then the second term becomes zero, the sum of squares is minimized when $y g a p_{t}-y g a p_{t}^{g}, \forall_{t}$, and the HP filter would return the original series ygapt as the growth component. Meanwhile, the second term is minimized when $y g a p_{t}^{g}-y g a p_{t-1}^{g}$ is the same ${ }_{t}$. The objective of the minimization problem is to select the trend component that minimize the sum of squared deviations from the observed ygap $_{t}$ series, subject to the constraint that changes in the trend component ( ${ }^{\text {ggap }}{ }_{t}^{g}$ ) vary gradually overtime.

\section{Results}

The output gaps are estimated for each country and results are presented below in Figure 1. Real GDP are in log values, constant 2005 USD prices. The countries are arranged according to their monetary policy framework in order to compare their performance. Real GDP and its estimated trends for each country are displayed in the top panels in all figures. Real GDP is measured on the vertical axis in all figures. The annual rates of inflation and the estimated changes in output gaps are displayed in the bottom panels. In all figures, output gap is measured on the left-hand side on the vertical axis in terms of growth rates. Inflation is measured on the right-hand side on the vertical axis in terms of percentage changes. Note that the scale for each country is different.

Based on the visual plots, the estimated trends are relatively smooth for countries under 'inflation targeting' and 'other' monetary policy framework for the period under study. For the countries under 'monetary aggregate target', there are some noticeable deviations between the actual and the estimated trend during certain years, particularly during early 1980s. These might be due to the rising oil price during this time because most countries under this category are oil producers.

There was a large negative output gap spikes during mid-80s in the countries under Exchange rate anchor framework, probably affected by the Persian Gulf War. The highest inflation spike at approximately 16 percent was recorded by Qatar in 2008 during global financial crisis. Indonesia was adversely affected by the 1997 Asian financial crisis in which there was the largest negative output gap and the highest inflation spike reaching almost 60 percent. Turkey, on the other hand, has high inflation and high fluctuations in output gaps estimations. Beginning mid-2000, inflation seems to stabilize at a much lower level. Pakistan shows rising inflation at the end of 2000s while Malaysia, with the largest negative output gap spike during 1997 Asian financial crisis, still have rising inflation even though output gaps 
are stable.

On the other hand, visual inspections on the output gap and inflation suggest that most of the inflation spikes tend to be associated with smaller spike in the output gaps. However, there are certain periods where the spikes in output gap are not accompanied by similar rise in inflation for some of the countries. We examine the output gap on level (instead of growth rates as shown here), and found that the rise in inflation in most cases occurred after the spike. This might be due to persistent large output gaps (PLOGs), in which the trade-off between inflation and unemployment is tight when output gaps are large but disinflation decelerates at very low inflation rates (R. A. , 2013). This might indicate that inflation, at both level and changes, are equally important to policy makers.

After mid-1990s, most countries under 'exchange rate anchor' arrangement, except Qatar, show almost similar patterns in their output gap changes. There is also a smoother trend between real and potential output. However, further empirical works are required to ascertain that output gaps are a good predictor for inflationary pressures for these countries.
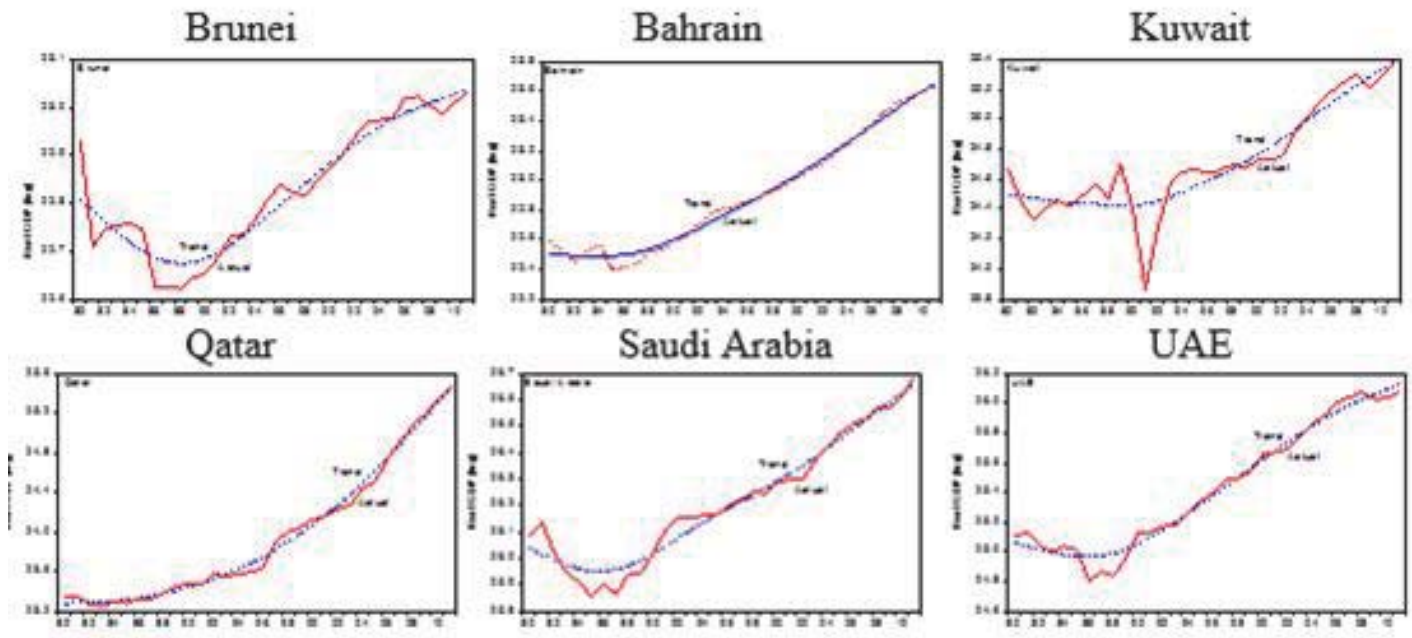

Saudi Arabia
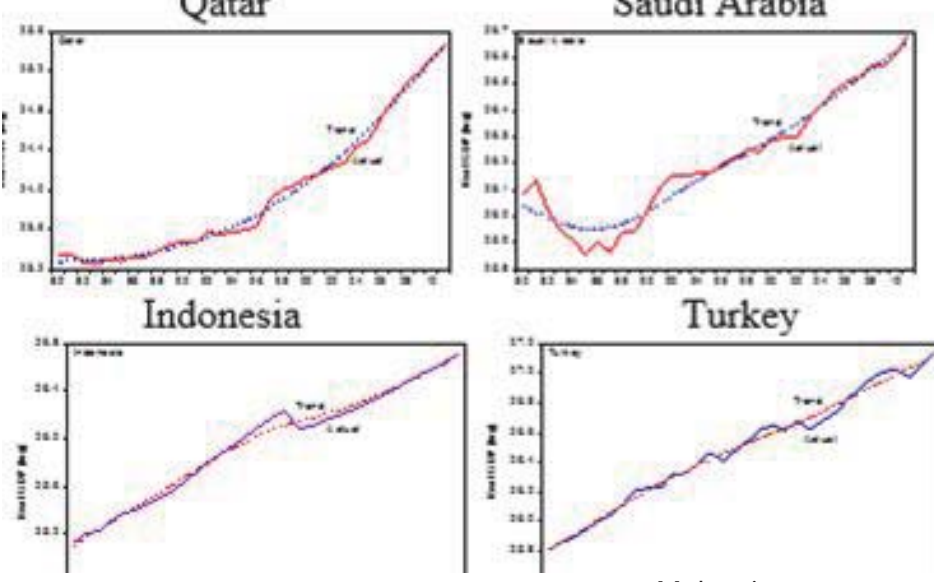

UAE

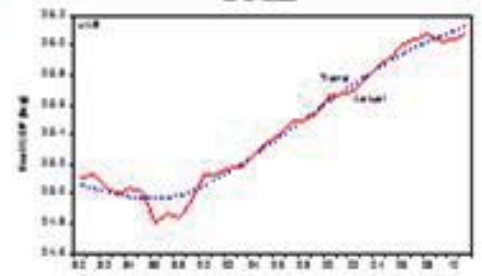

Turkey
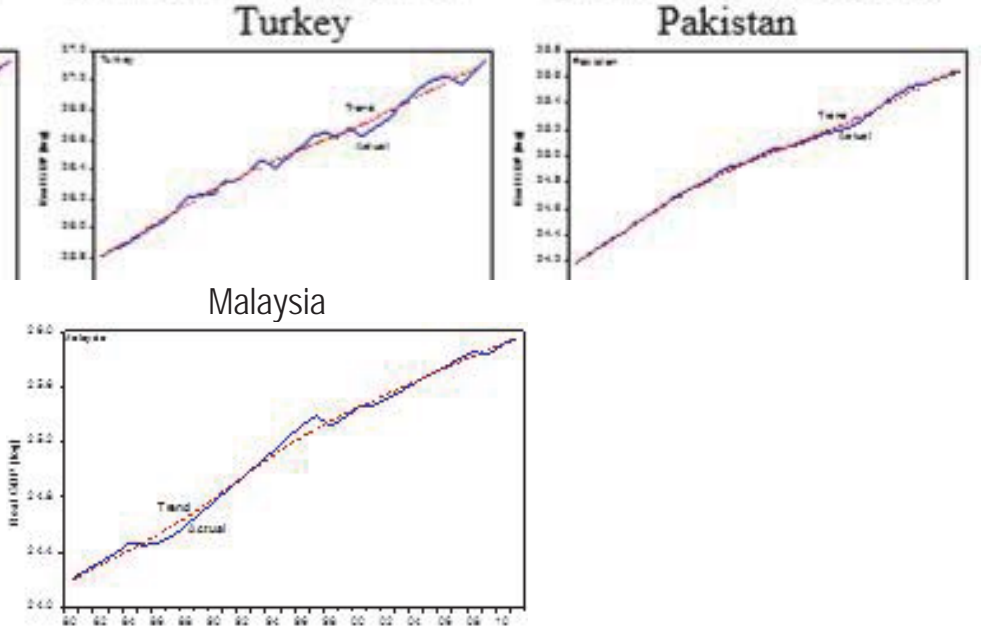

Figure 1: Real GDP and Estimated Trends, 1980 - 2011

Table 2 below shows the GDP and output gap average annual growth rate for the period under study. Based on the estimations, the average growth rate of the output gap estimates is approximately $1 \%$ over the period of study. The GDP growth rate is $4 \%$ and inflation is $8.58 \%$. Turkey and Indonesia, both adopting Inflation Targeting policy framework, registered double-digit inflation rate. Qatar registered highest average growth rate at 7. 19\%, followed by Malaysia with 5. $97 \%$ and Indonesia at 5. 16\%. For the 2000s period, Turkey inflation management policy saw an almost 300\% reduction of the growth rate as compared to the 1980-1990 period. Bahrain, Kuwait, Qatar and Indonesia has annual growth rate in GDP exceeding $5 \%$ in the 2000 s. 
Table 2: GDP and Output Gap, Average Annual Growth Rate,1980 - 2011

\begin{tabular}{|c|c|c|c|c|c|c|c|c|c|c|c|c|}
\hline \multirow[b]{2}{*}{ Country } & \multicolumn{4}{|c|}{ Full Sample, 1980 - 2011} & \multicolumn{4}{|c|}{1980 - 1990s } & \multicolumn{4}{|c|}{$2000 \mathrm{~s}$} \\
\hline & $\begin{array}{c}\text { Actual } \\
\text { GDP }\end{array}$ & \begin{tabular}{|l|} 
Trend \\
GDP
\end{tabular} & CPI & $\begin{array}{l}\text { Output } \\
\text { Gap }\end{array}$ & $\begin{array}{l}\text { Actual } \\
\text { GDP }\end{array}$ & Trend GDP & CPI & $\begin{array}{l}\text { Output } \\
\text { Gap }\end{array}$ & $\begin{array}{l}\text { Actual } \\
\text { GDP }\end{array}$ & $\begin{array}{l}\text { Trend } \\
\text { GDP }\end{array}$ & CPI & $\begin{array}{l}\text { Output } \\
\text { Gap }\end{array}$ \\
\hline $\begin{array}{c}\text { Average } \\
\text { for all countries }\end{array}$ & 4. 06 & 1. 38 & 8. 58 & 1. 01 & 3. 17 & 1. 29 & 12. 19 & 1.00 & 5. 37 & 1. 57 & 5.58 & 1. 01 \\
\hline \multicolumn{13}{|c|}{ Countries under Exchange rate anchor arrangement } \\
\hline Bahrain & 3.49 & 1.45 & 1.61 & 0.99 & 2.26 & 1.30 & 1.70 & 0.99 & 5.56 & 1.73 & 1.44 & 1.00 \\
\hline Brunei & 0.22 & 1.08 & 1.29 & 1.00 & -0.59 & 1.03 & 1.65 & 1.00 & 1.58 & 1.16 & 0.70 & 1.01 \\
\hline Kuwait & 2.92 & 1.30 & 3.58 & 0.99 & 1.01 & 1. 11 & 3.63 & 0.98 & 6.09 & 1.68 & 3.51 & 1.00 \\
\hline Qatar & 7.19 & 1.94 & 3.93 & 1.00 & 3.83 & 1.44 & 3.47 & 1.00 & 12.79 & 3.11 & 4.71 & 0.99 \\
\hline Saudi Arabia & 2.20 & 1.19 & 1.06 & 1.00 & 1.24 & 1.11 & 0.50 & 0.99 & 3.81 & 1.34 & 1.99 & 1.01 \\
\hline UAE & 4.16 & 1.36 & 4.50 & 0.99 & 3.85 & 1.27 & 4.34 & 0.99 & 4.68 & 1.52 & 4.78 & 0.99 \\
\hline \multicolumn{13}{|c|}{ Countries Under Monetary Aggregate Target Framework } \\
\hline Pakistan & 4.96 & 1.60 & 8.27 & 1.00 & 5.29 & 1.60 & 8.47 & 1.00 & 4.41 & 1. 48 & 7.92 & 1.00 \\
\hline \multicolumn{13}{|c|}{ Inflation Targeting Framework } \\
\hline Indonesia & 5.16 & 1.01 & 10.53 & 1.01 & 4.15 & 1.14 & 15.32 & 0.99 & 5.25 & 1.105 & 7.93 & 1.00 \\
\hline Turkey & 4. 30 & 1.14 & 47.86 & 0.99 & 3.44 & 1.11 & 79.08 & 1.02 & 4.61 & 1. 11 & 20.55 & 1.01 \\
\hline \multicolumn{13}{|c|}{ Other Monetary Policy Arrangement } \\
\hline Malaysia & 5.97 & 1.69 & 3.13 & 1.10 & 7.25 & 1.80 & 3.70 & 1.06 & 4.96 & 1.52 & 2.24 & 1.10 \\
\hline
\end{tabular}

Notes: The weighted average is based on GDP for the period $1980-2011$, normalized to 1 . The weights are calculated for each individual country based on monetary policy classifications. Figures are average values.

In short, countries under 'exchange rate anchor' arrangement might learn from both the 'inflation targeting' and 'other' monetary policy framework. The literature suggests that output gaps have valuable information content about movement in price and wage inflation (de Brouwer, 1998). However, the information should be used along with other broad set of information in policy setting. Assessing model predictions based on output gap produce better results when policy has clear targets.

\section{Conclusion}

The study compares the size of output gaps in ten selected OIC sukuk issuing member countries. The findings reveal that Bahrain, Pakistan and Malaysia have smooth trend between real GDP and its trends. Some of the countries under study display similar patterns of business cycles. Towards mid-2000s, most countries display fewer fluctuations in business cycles and changes in inflation. Indonesia seems to be able to track inflation well based on the visual plot of output gaps estimations. Hence, the results suggest that output gap estimations contain key information for monetary policy.

The output gap is an important concept in the preparation of inflation forecasts and assessments of the economic outlook and the stance of macroeconomic policies. The size of output gap helps policy-makers design appropriate policies to sustain economic growth in the long run without inducing inflation. Therefore, more accurate forecasts of inflation should help improve formulation of monetary policy in a particular economy.

For future research, the output gap estimations could be empirically decomposed into observable components such as inflation, unemployment, capacity utilisation or others in order to determine which components are important during high and low business cycle frequencies. The ultimate aim is to be included in the international currency basket. In addition, the output gaps estimations could be included in the empirical inflation equation to reduce ex-post prediction error.

\section{References}

Andrle. M. , 2013. What is in Your Output Gap? Unified Framework and Decomposition Into Observables. International Monetary Fund Working Paper WP/13/105.

deBrouwer, G. , 1998. Estimating Output Gaps. Research Discussion Paper 9809, Economic Research Department, Reserve Bank of Australia.

Bukhari, S. A. H. and Ullah, K. S. , 2008. Estimating Output Gap for Pakistan Economy: Structural and Statistical Approaches. Research Department, State Bank of Pakistan, Karachi, Pakistan.

Bussiere, M. , 2006. Exchange Rate Pass-Through to Trade Prices: The Role of Non-Linearities and Asymmetries, European Central 
Bank, Frankfurt: Germany.

Claus, I. , 2000. Is the Output Gap a Useful Indicator of Inflation? Reserve Bank of New Zealand, Discussion Paper Series No: 2000/05.

Coe, D. T. and McDermott, C. J. 1997. Does the Gap Model Work in Asia? IMF Staff Papers, 44 (1): 59-80.

Marrewijk, C. V. , 2005. Basic Exchange Rate Theories. Tinbergen Institute Discussion Paper, TI 2005-024/2, Amsterdam.

Meltzer, A. H. , 1993. Real Exchange Rates: Some Evidence From the Postwar Years, Review-Federal Reserve Bank of St Louis, 75 (2), March/April: USA.

Osman, M. 2011. Potential Output and Output Gap for the Gulf Cooperation Council (GCC) Countries: Alternative Methods, Journal of Economic and Social Research, 13 (2): 29-44.

Rajan, R. S. 2004. Choosing an Appropriate Exchange Rate Regime for Small Open Emerging Economies, Briefing Notes in Economics, 59. Available at: http: //www. richmond. ac. uk/bne. [Accessed on August 8, 2005]

R. A. 2013. Output Gaps, When the Fed Fights, it Wins, The Economist, March 6 2013. Available at: http: //www. economist. com/blogs/freeexchange/2013/03/output-gaps. [Accessed on 6 July 2013. ]

SESRICa, 2012. Exchange Rate Regimes in the OIC Member Countries, OIC Outlook Series, February 2012, Organisation of Islamic Cooperation and Statistical, Economic and Social Research Training Centre for Islamic Countries (SESRIC), Ankara: Turki.

SESRICb, 2012. Annual Economic Report on the OIC Countries 2012. Statistical Economics and Social Research and Training Center for Islamic Countries (SESRIC), Ankara: Turkey.

Slevin, G. , 2001. Potential Output and the Output Gap in Ireland, Central Bank of Ireland Technical Paper, 5/RT/01.

Stockman, A. C. ,1999. Choosing an Exchange Rate System. Journal of Banking and Finance, 23: 1483-1498. 